University of Nebraska - Lincoln

DigitalCommons@University of Nebraska - Lincoln

$5-31-2018$

\title{
Evaluation of Potential Translocation Sites for an Imperiled Cyprinid, the Hornyhead Chub
}

Brian T. Hickerson

Annika W. Walters

Follow this and additional works at: https://digitalcommons.unl.edu/usgsstaffpub

Part of the Geology Commons, Oceanography and Atmospheric Sciences and Meteorology Commons, Other Earth Sciences Commons, and the Other Environmental Sciences Commons

This Article is brought to you for free and open access by the US Geological Survey at DigitalCommons@University of Nebraska - Lincoln. It has been accepted for inclusion in USGS Staff -- Published Research by an authorized administrator of DigitalCommons@University of Nebraska - Lincoln. 


\title{
Evaluation of Potential Translocation Sites for an Imperiled Cyprinid, the Hornyhead Chub
}

\author{
Brian T. Hickerson* \\ Wyoming Cooperative Fish and Wildlife Research Unit, Department of Zoology and Physiology, University of Wyoming, \\ Laramie, Wyoming 82071, USA
}

\author{
Annika W. Walters \\ U.S. Geological Survey, Wyoming Cooperative Fish and Wildlife Research Unit, Department of Zoology and Physiology, \\ University of Wyoming, Laramie, Wyoming 82071, USA
}

\begin{abstract}
Translocation of isolated species into suitable habitats may help to secure vulnerable, geographically limited species. Due to the decline of Wyoming Hornyhead Chub Nocomis biguttatus, conservation actions, such as the translocation of populations within the plausible historical range, are being considered to improve population redundancy and resiliency to disturbance events. Translocation of Wyoming Hornyhead Chub must be rigorously evaluated because a hatchery stock does not exist, so all fish used in translocations will come from the wild population. We present an approach to identify the best available translocation sites prior to translocation efforts taking place. We evaluated fish community composition and habitat conditions at 54 potential translocation sites for Hornyhead Chub within 12 streams of the North Platte River basin of Wyoming. We used two analyses to identify translocation sites that were most similar to currently occupied Hornyhead Chub sites on the Laramie River: hurdle models to predict hypothetical abundance of Hornyhead Chub at translocation sites and nonmetric multidimensional scaling with fish community and habitat conditions. Presence and abundance of Hornyhead Chub were positively related to a lack of nonnative predators and to habitat features characteristic of backwater and velocity refuge habitats (e.g., minimum water velocity and width-to-depth ratio). We used a rank scoring system to weight the outcomes of each analysis, and the highest-ranking translocation sites occurred at a historically occupied locality, the Sweetwater River. Our approach may be appropriate for other at-risk species with isolated distributions and little historical data.
\end{abstract}

Many native fish populations are undergoing abundance declines and local extirpation due to stochastic disturbance events, nonnative species introductions, and habitat degradation (Brown et al. 2001; Lyon and O'Connor 2008). Wildfire, drought, floods, chemical spills, and nonnative species introductions can rapidly alter aquatic ecosystems and can be catastrophic in nature (Brown et al. 2001; Roghair et al. 2002; Cucherousset and Olden 2011). Land use changes, dam and reservoir construction, and water diversion cause habitat degradation and flow alteration, which lead to long-term fish population declines (Gido et al. 2010). Isolated populations may be especially susceptible to disturbance because of small population sizes, fragmented distributions on the landscape, and limited dispersal abilities (Fagan 2002; Perkin et al. 2014).

Translocation of isolated populations into suitable habitats may help to secure vulnerable, geographically limited species. Successful translocation efforts require evaluation at many steps, including sufficient population size and genetic variability of donor populations, availability of suitable translocation sites, feasibility of carrying out a translocation effort, and monitoring of translocated populations for survival and recruitment (Figure 1; George et al. 2009; Dunham et al. 2011). Managers have advocated for evaluating site suitability and project feasibility before translocations take place (Macdonald et al. 2000; Armstrong and Seddon 2008; Dunham et al. 2011). Evaluating potential translocation sites for the ability to support a viable population of target organisms can help to avoid wasting valuable resources in areas where the potential for success is low (Macdonald et al. 2000; Dunham et al. 2011).

*Corresponding author: bhicker1@uwyo.edu

Received May 31, 2018; accepted December 1, 2018 
Translocation success is a function of the biotic and abiotic conditions present at translocation sites and the biotic and abiotic tolerances of target species. Suitable translocation sites must provide access to the food resources and habitats that are required to carry out key life history events, including habitat for spawning and juvenile rearing (George et al. 2009). Pre-existing fish communities at translocation sites must also allow for the establishment of target species (Al-Chokhachy et al. 2009; Spurgeon et al. 2015). Presence of nonnative fishes may negatively affect translocation success if competition with or predation on target species is likely to occur (Al-Chokhachy et al. 2009; Cochran-Biederman et al. 2015; Spurgeon et al. 2015). Conversely, the presence of species with habitat requirements similar to those of the target species might indicate underlying suitable habitat conditions (Fausch et al. 1990). Translocation approaches that incorporate both abiotic and biotic components in a multi-level framework will have a higher potential for success (Al-Chokhachy et al. 2009; George et al. 2009).

We evaluated potential translocation sites for the Hornyhead Chub Nocomis biguttatus, a species of conservation concern in Wyoming. The objectives of this study were to (1) evaluate fish community composition and habitat attributes driving Hornyhead Chub distribution and abundance in the Laramie River and (2) identify translocation sites that are most likely to support a population of Hornyhead Chub based on the similarity of fish community and habitat to those at currently occupied sites and based on model-predicted Hornyhead Chub abundance. The approach we present may be useful for the evaluation of translocation sites for other species with limited distributions and little historical data and can improve management and recovery efforts for at-risk species.

\section{METHODS}

Study species. - The Hornyhead Chub occurs from the Ozarks to the Midwest, with a few disjunct populations in the middle and lower Missouri River drainages (Lachner and Jenkins 1971). They were historically more widely distributed, with populations throughout the Platte River drainage of western Nebraska, western Kansas, eastern Colorado, and eastern Wyoming (Propst and Carlson 1986; Baxter and Stone 1995; Cross and Collins 1995). Platte River populations in Nebraska, Kansas, and Colorado have been extirpated, so presently Hornyhead Chub are limited to two populations in Wyoming. Despite isolation from the core range, the limited genetic data available suggest that Wyoming Hornyhead Chub are not genetically distinct and fall within the Northern Ozarks-Great

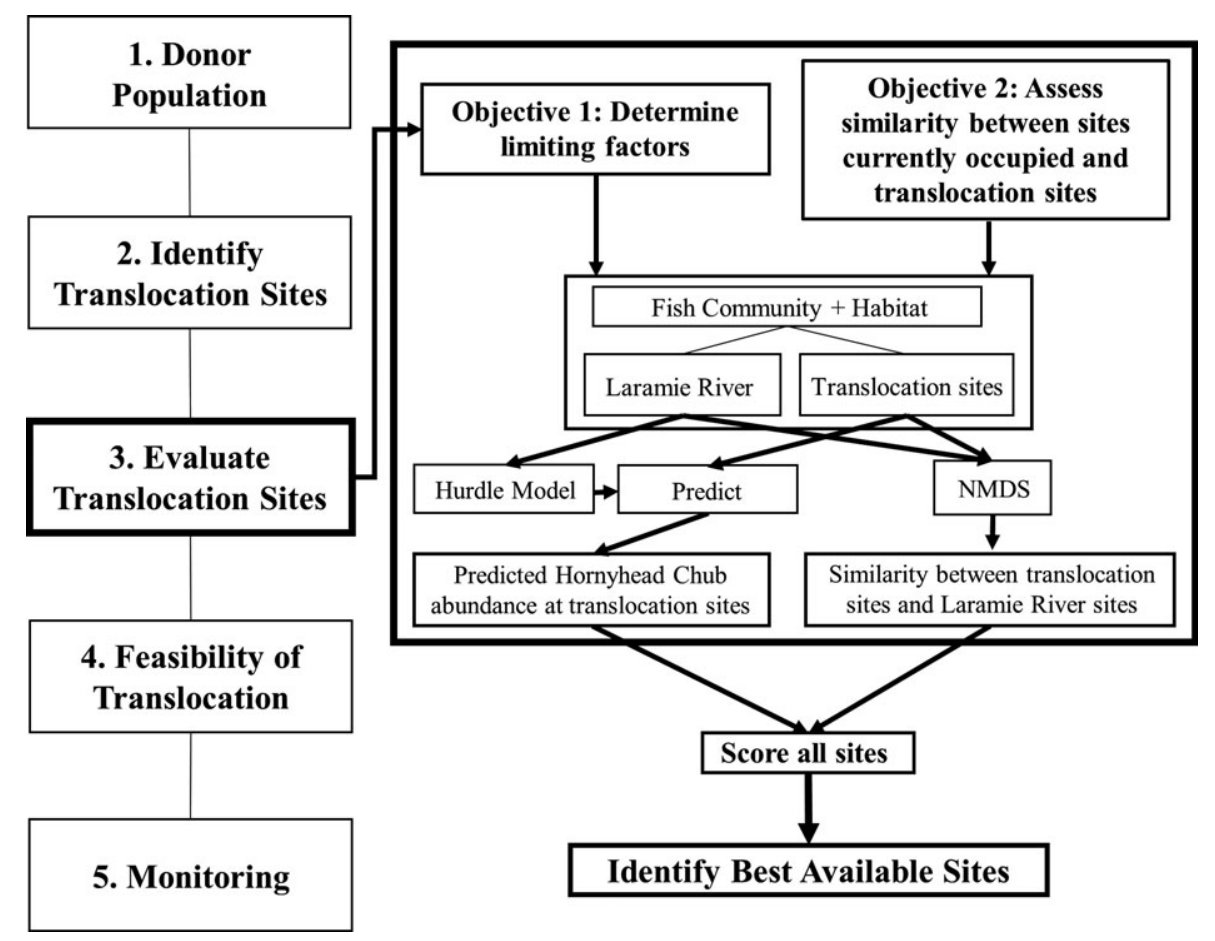

FIGURE 1. Conceptual diagram of major steps in the translocation process from identifying the donor population through monitoring. We focus specifically on the third step (evaluation of translocation sites) and present an outline of our approach, including data types and analysis methods used to accomplish each objective (NMDS = nonmetric multidimensional scaling). 
Plains-Upper Midwest clade (Echelle et al. 2014). The substantial reduction in Hornyhead Chub distribution within the Platte River drainage is attributable to competition and to increased agriculture and drought, which have reduced the availability of the cool, clear, low-silt perennial streams favored by Hornyhead Chub (Lachner and Jenkins 1971). Hornyhead Chub are sensitive to disturbance, and population extirpation has been associated with habitat and flow alteration due to urbanization, suburbanization, impoundment, and agriculture (Fitzgerald et al. 1998; Mammoliti 2002; Miltner et al. 2004). Catastrophic events have also led to Hornyhead Chub population extirpations, including a mine waste spill on Boulder Creek, Colorado, and the 2012 Arapahoe Fire on the North Laramie River, Wyoming (Propst and Carlson 1986; WGFD 2015).

Hornyhead Chub prefer relatively clear, cool streams of small to moderate size with low to moderate gradients and access to gravel substrates for nest building (Lachner and Jenkins 1971; Vives 1990; Baxter and Stone 1995). Preferred streams generally have consistent flow with a mixture of riffles and pools; turbid waters or streams with high loads of fine silt are avoided (Lachner and Jenkins 1971). Hornyhead Chub are typically considered coolwater fish, with spawning taking place when spring water temperatures are between $16^{\circ} \mathrm{C}$ and $26^{\circ} \mathrm{C}$ (Vives 1990). Hornyhead Chub have been documented to share spawning nest sites with the Common Shiner Luxilus cornutus (Vives 1990) and to be negatively affected by the presence of nonnative predatory fish (Bestgen 2013; Hickerson 2018).

Wyoming populations of Hornyhead Chub historically occupied a variety of stream habitats from small spring creeks (Box and Rawhide creeks) to moderate-sized, canyon-bound streams (North Laramie River) to larger rivers (Laramie and Sweetwater rivers; Baxter and Stone 1995). It is difficult to know whether conditions leading to extirpation at historical localities have improved sufficiently to allow re-establishment because the cause of extirpation at most localities is unknown (Cochran-Biederman et al. 2015). Currently, there are two Wyoming populations: one occupying approximately $42 \mathrm{~km}$ of the Laramie River; and another, reintroduced population in the North Laramie River (Bestgen 2013; WGFD 2015). The North Laramie River population was translocated from the Laramie River in 2015 once habitat had sufficiently recovered from the 2012 Arapahoe Fire; natural reproduction in the North Laramie River was documented in 2017 (Hickerson 2018). The main factors limiting the Laramie River Hornyhead Chub population appear to be habitat fragmentation upstream (Wheatland Tunnel Diversion barrier) and the presence of Smallmouth Bass Micropterus dolomieu downstream (Hickerson 2018). Recent expansion of Smallmouth Bass in the Laramie River has been especially concerning, as (1) this species is a novel predator in the system, (2) the Laramie River has limited vegetative cover for refuge, and (3) a diversity of other small fish species to serve as a predatory buffer is lacking. A small, natural waterfall barrier currently limits the upstream distribution of Smallmouth Bass. At this time, a hatchery stock of Hornyhead Chub does not exist to support conservation efforts. Any future translocation efforts will use fish from the limited Laramie River population and thus will need to be rigorously evaluated to maximize the potential for success.

Study area. - We collected data at three study areas within the North Platte River basin of Wyoming: the Laramie River, 12 potential translocation streams, and the North Laramie River (Figure 2). We sampled a 42$\mathrm{km}$ reach of the Laramie River as it flows through the Laramie Range from the Wheatland Tunnel Diversion downstream to near Palmer Canyon Road. This reach is the current known distribution of Hornyhead Chub in the Laramie River (Bestgen 2013). We evaluated abundance, habitat use, and fish community associations of Hornyhead Chub at 42 sites in the Laramie River study area. The site selection procedure is detailed in the next section.

The translocation streams included 12 major perennial streams within the plausible historical range of the Hornyhead Chub. We chose translocation streams based on a number of subjective criteria: streams with historical accounts of Hornyhead Chub (Sweetwater River: Girard 1856; Rawhide Creek: Baxter and Stone 1995), major perennial streams with headwaters in the Laramie Range (Deer, Box Elder, La Prele, Wagonhound, La Bonte, Horseshoe, Cottonwood, and Horse creeks), and streams in close proximity to the Hornyhead Chub-occupied reach of the Laramie River (Duck Creek and upper Laramie River [between Wheatland Reservoir Number 2 and the Wheatland Tunnel Diversion]; Figure 2). To focus our sampling, we only considered reaches of stream below $2,100 \mathrm{~m}$ in elevation because Hornyhead Chub have not been documented above $1,969 \mathrm{~m}$ in Wyoming (Bestgen 2013). To broadly evaluate potential translocation streams, we sampled two sites (an upper site and a lower site) on each of the 12 translocation streams in 2016, for a total of 24 sites. After preliminary nonmetric multidimensional scaling (NMDS) analysis of 2016 habitat and fish community data, we decided to focus our 2017 effort on six sites on each of the five translocation streams that were most similar to Hornyhead Chub-occupied Laramie River sites based on ordination distance: the Sweetwater River and Deer, Box Elder, Horseshoe, and Horse creeks. We sampled a total of 54 translocation sites between 2016 and 2017.

In the North Laramie River, we sampled four sites within a $22.7-\mathrm{km}$ reach from the Medicine Bow National 


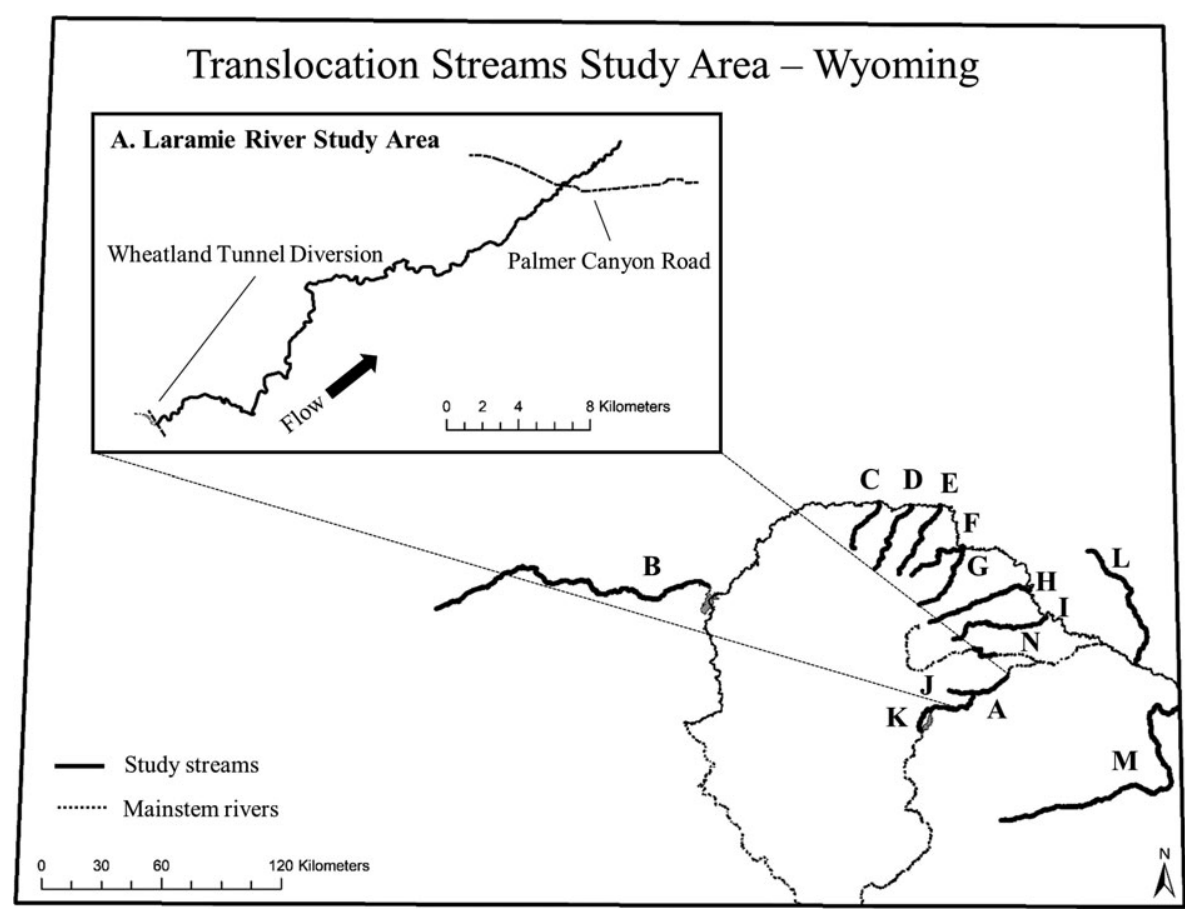

FIGURE 2. Locations of study areas in the Laramie River, translocation streams, and North Laramie River, Wyoming. Inset shows the Laramie River (A) between the Wheatland Tunnel Diversion (the upstream limit of Hornyhead Chub distribution) and Palmer Canyon Road (the proximate downstream limit of Hornyhead Chub distribution). The 12 translocation streams within the North Platte River watershed are shown from upstreammost to downstream-most: Sweetwater River (B), Deer Creek (C), Box Elder Creek (D), La Prele Creek (E), Wagonhound Creek (F), La Bonte Creek (G), Horseshoe Creek (H), Cottonwood Creek (I), Duck Creek (J), upper Laramie River (K), Rawhide Creek (L), and Horse Creek (M). Also shown is the North Laramie River study area $(\mathrm{N})$.

Forest boundary downstream to near Fletcher Park Road. This $22.7-\mathrm{km}$ reach represents the approximate distribution of Hornyhead Chub prior to the Arapahoe Fire of 2012 (Bestgen 2013). We only collected habitat data at sites in the North Laramie River study area; the broader fish community is still in the process of recolonizing the stream, and therefore the fish community may not yet be representative of habitat conditions. North Laramie River sites were important to include in this study because persistence and reproduction of reintroduced Hornyhead Chub have been documented in this area.

Site selection.-For each of the 14 streams and two sampling years, we split a National Hydrography Dataset (NHD) flow line (NHDplus version 2) into 100-m-long segments in ArcGIS version 10.3 (ESRI, Redlands, California), assigned unique identification numbers to each segment, and randomly selected sites to sample. When selected sites fell on private land, we contacted landowners for access. If permission for access was denied or if sites were located farther than $8.05 \mathrm{~km}(5 \mathrm{mi})$ from vehicle access, we proceeded to the next randomly chosen site in the sequence until we secured access to the required number of sites for each stream. If sites were deemed too difficult to sample in the field (i.e., excessive depths or dangerous conditions), we continued upstream until site conditions allowed for sampling. We chose 100-m-long sites to conduct comparisons of fish community and habitat at the same scale between Laramie River sites and translocation sites. An additional practical constraint on site length was the amount of time and personnel required to carry out three-pass depletion at Laramie River sites.

Habitat data collection. - We collected a wide range of habitat data in order to quantify both expected and unexpected habitat associations of Hornyhead Chub. We classified macrohabitat (pool, run, riffle, or cascade) as a percentage of reach length according to a simplified version of the Hawkins habitat classification system (Hawkins et al. 1993: their Table 2). We placed 10 transects perpendicular to the direction of flow every $10 \mathrm{~m}$, beginning at $5 \mathrm{~m}$ upstream of our starting point. At each transect, we measured stream width and recorded cover as the width of each transect where one of four cover types (boulder cover, overhead cover, undercut bank, or woody debris) was present. We evaluated bank stability where each transect met a bank; if the majority of a 1-m section of the bank perpendicular to the transect was bound by roots or vegetation or consisted of boulder or bedrock substrate, it was classified as stable (K. Bestgen, Colorado State University, personal communication). We recorded measures of depth, velocity, and substrate at 10 
equidistant points along each of 10 transects, thereby yielding a total of 100 measurements for each variable. The nearest upstream substrate to the base of the top-setting wading rod was classified into a substrate size category according to a modified Wentworth classification (Cummins 1962).

We collected temperature data at each potential translocation stream from June to October by deploying at least one temperature logger (Onset HOBO Pendant 64k) in 2016 and three temperature loggers in 2017, with the goal of deploying upper, middle, and lower loggers in each stream, depending on landowner permission. Two temperature loggers were deployed in the Laramie River during both years. Because we did not have temperature loggers at all Laramie River sites, we used a multiple regression model following the procedure outlined by Isaak et al. (2009) to estimate stream temperature at each site. The model included variables for elevation, slope, and total drainage area that were derived from NHD attributes. We trained the model by using our temperature logger data and applied the model to all translocation sites to estimate mean August stream temperature, which might identify upper thermal limitations. Linear regression of measured versus predicted temperatures suggested that the model fit the data well (intercept $=0.28$; slope $=0.98 ; R^{2}=26.65 \%$ ).

Fish community sampling. - We collected fish community data at all sites except the North Laramie River, with the goal of characterizing both the relative abundance and composition of species present. We set block nets at the upstream and downstream extent of the 100-m sampling reach. We carried out a single pass of electrofishing effort with two backpack electrofishers (Smith-Root LR-24) within the blocked reach and attempted to capture all fish observed. All captured fish were identified to species and counted. At Laramie River sites, we carried out three passes of electrofishing effort to obtain depletion estimates of Hornyhead Chub abundance. Captured fish were held in instream live wells downstream of the blocked reach until all passes were completed; the fish were then released back into the study reach. A single Laramie River site from 2017 was excluded from analysis because an equipment malfunction prevented us from achieving depletion.

Habitat variables. - We derived a suite of general habitat variables from field-measured habitat data for use in analyses. We calculated substrate diversity with Shannon's diversity index using all 100 substrate measures at a site and the "diversity" function in the "vegan" package (Oksanen et al. 2017). We calculated discharge using measured stream width, velocity, and depth for each of the 10 transects at a site. We calculated maximum and minimum values of depth and velocity for each of the 10 transects and averaged all 10 values of each variable to derive the mean site maximum depth, mean site maximum velocity, and mean site minimum velocity. We used all measurements of substrate, total cover, boulder cover, overhead cover, undercut bank cover, woody debris cover, depth, width, velocity, and discharge at a site to calculate site mean values. Width-to-depth ratios were calculated using the mean width and mean depth for each site. We estimated stream slope by creating points at $500-\mathrm{m}$ intervals along each NHD flow line, overlaying the points with a 10-m-resolution digital elevation model (DEM; U.S. Geological Survey National Elevation Dataset), and extracting elevation values to the points. We evaluated slope at 500-m increments because minor deviations between the spatial configuration of NHD flowlines and the DEM can result in positive slopes at shorter reach lengths (i.e., $100 \mathrm{~m}$ ).

Hurdle model. - We modeled Hornyhead Chub presence and abundance by using hurdle models. We initially attempted to use a negative binomial generalized linear model (GLM) and a zero-inflated negative binomial GLM but found the fit-and, more importantly, the interpretation- to be difficult. Hurdle models are two-part models in which the first part is a logistic regression that accounts for factors leading to zeros and the second part is a GLM that accounts for factors influencing abundance (Potts and Elith 2006). Hurdle models are ideal for situations wherein one process appears to be influencing presence while a separate process seems to influence abundance (Zuur et al. 2009), and we had evidence that the absence of Hornyhead Chub was mostly related to Smallmouth Bass presence (Hickerson 2018). We created hurdle models using the "hurdle" function in the R package "pscl" (Jackman 2017). Zero processes were modeled with logistic regression using a binomial error distribution, and count processes were modeled with a negative binomial error distribution to account for overdispersion (Zuur et al. 2009). We selected among candidate models by using Akaike's information criterion corrected for small sample sizes $\left(\mathrm{AIC}_{c}\right.$; Burnham and Anderson 2002). We used a bootstrap method to compare fitted versus predicted values of the top model by using root mean square error (RMSE); Pearson's product-moment correlation coefficient (Pearson's $r$ ) and Spearman's rank correlation coefficient $\left(r_{S}\right)$ were used to assess predictive power (Streyerberg et al. 2001; Potts and Elith 2006). We used three-pass depletion (Carle-Strub method) to estimate the abundance of Hornyhead Chub at Laramie River sites using the "removal" function in the Fisheries Stock Analysis (FSA) package (Ogle 2017).

Based on our observations in the field and previous research, we developed a number of hypotheses about habitat conditions and fish community composition that might influence both the presence and abundance of Hornyhead Chub in the Laramie River (Table 1). The zero-process terms were the same for all models, with the count processes falling into four broad categories of what 
HICKERSON AND WALTERS

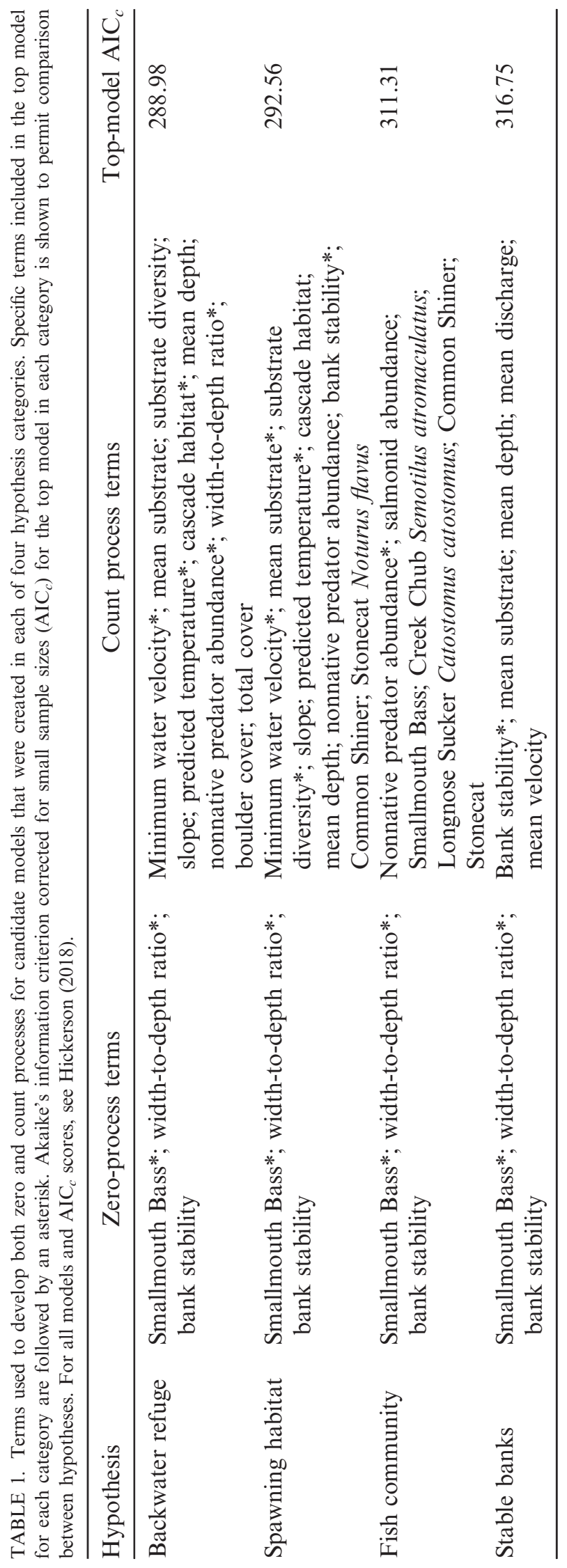


could be limiting Hornyhead Chub abundance: fish community, spawning habitat, backwater refuge, and stable banks. For the zero-process term, we had observed that Hornyhead Chub were typically absent from sites where Smallmouth Bass were present, but sites where both Smallmouth Bass and Hornyhead Chub were absent appeared to be deeper and narrower than other sites. In addition, previous research on the Laramie River and North Laramie River populations used logistic regression to identify habitat and fish community factors most influencing the presence of Hornyhead Chub and concluded that bank stability was the only habitat term common to all of the top models, with the terms water depth and abundance of nonnative predators also being included in the top Laramie River model (Bestgen 2013). In an effort to ensure that we were not excluding any potentially important variables from the zero component of our hurdle models, we conducted exploratory univariate logistic regressions between Hornyhead Chub presence and all habitat and fish community terms. We failed to find any significant terms $(P<0.05)$ that were not also correlated with the abundance of Smallmouth Bass $(r>0.50)$, so we used the abundance of Smallmouth Bass, width-to-depth ratio, and bank stability as our potential zero-hurdle terms. Our bank stability hypotheses included bank stability and other terms thought to be important for Hornyhead Chub, such as discharge and mean substrate size category (Bestgen 2013). Our fish community hypotheses consisted of models with terms for fish species having potential negative effects on Hornyhead Chub (i.e., nonnative predators) or fish species having potential positive associations with Hornyhead Chub because of similar habitat requirements (e.g., Common Shiner and Stonecat). Spawning habitat hypotheses included terms that might be important for nest location, building, and maintenance (e.g., water velocity, substrate size, and substrate diversity). Backwater refuge hypotheses contained terms describing areas that Hornyhead Chub could use as refuge from predators or as velocity shelters during high flows, such as minimum water velocity, width-to-depth ratio, and abundance of nonnative predators. A full list of models is provided by Hickerson (2018).

We estimated the Hornyhead Chub abundance that could hypothetically exist at each 100-m translocation site using the model with the lowest $\mathrm{AIC}_{c}$ value. Translocation sites were ranked by predicted abundance of Hornyhead Chub, with the site of highest predicted abundance receiving a rank of 1 and the site of lowest predicted abundance receiving a rank of 54 .

Nonmetric multidimensional scaling.-We assessed the relative similarity of fish community composition and habitat conditions at translocation sites and Laramie River sites by using NMDS ordinations (Rowe et al. 2009). Nonmetric multidimensional scaling is frequently used to calculate similarities between sites in a low-dimensional, easy-to-visualize configuration (Zuur et al. 2007). We calculated a NMDS ordination for fish community by using two dimensions and a Bray-Curtis dissimilarity index (Bray and Curtis 1957). Fish community data were normalized to proportional catch prior to their inclusion in NMDS analyses by dividing the number of individuals of each species at a site by the total catch at that site (Ruetz et al. 2007). We calculated a NMDS ordination for all habitat variables using two dimensions and a Euclidean distance matrix because habitat variables were normalized using $\log (x+1)$ transformation (Dunn and Angermeier 2016). We calculated stress values to assess how well NMDS configurations preserved the original dissimilarity distances. We also created Shepard plots of original dissimilarity matrix distances against actual NMDS distances and used $R^{2}$ values to assess configurations. The NMDS analyses were carried out in the R package "vegan" (Oksanen et al. 2017).

We calculated the average NMDS coordinates of all Hornyhead Chub-occupied sites to determine the mean location of those sites in ordination space for both fish community and habitat ordinations. We measured the distance from the mean location of Hornyhead Chuboccupied sites to all translocation sites as a measure of relative similarity between Hornyhead Chub-occupied sites and translocation sites for both fish community and habitat ordinations. Translocation sites were given ranks based on relative similarity, with the closest (most similar) site receiving a rank of 1 and the farthest (least similar) site receiving a rank of 54 .

Rank scoring.- Rank totals were calculated for each site by adding the ranks from the two ordinations and the hurdle model. We chose this multi-method approach to account for variability in site ranks across analyses. We calculated values of $r_{S}$ (1) between ranks for each pair of methods and (2) between ranks for each method and rank totals. All statistical analyses were carried out in $\mathrm{R}$ version 3.4.2 (R Core Team, Vienna).

\section{RESULTS}

Backwater refuge models consistently outperformed spawning habitat, stable bank, and fish community hypotheses. Our top hurdle model was from the backwater refuge hypothesis category and had an $\mathrm{AIC}_{c}$ value of 288.97 (number of model parameters $[K]=10$; $\mathrm{AIC}_{c}$ weight $=0.232$; Table 1). The zero process included the terms Smallmouth Bass and width-to-depth ratio, and the count process included the following terms: total nonnative predators, minimum water velocity, width-to-depth ratio, amount of cascade habitat, and predicted mean August stream temperature (Table 1). Comparison of model-bootstrapped fitted and predicted values resulted in 


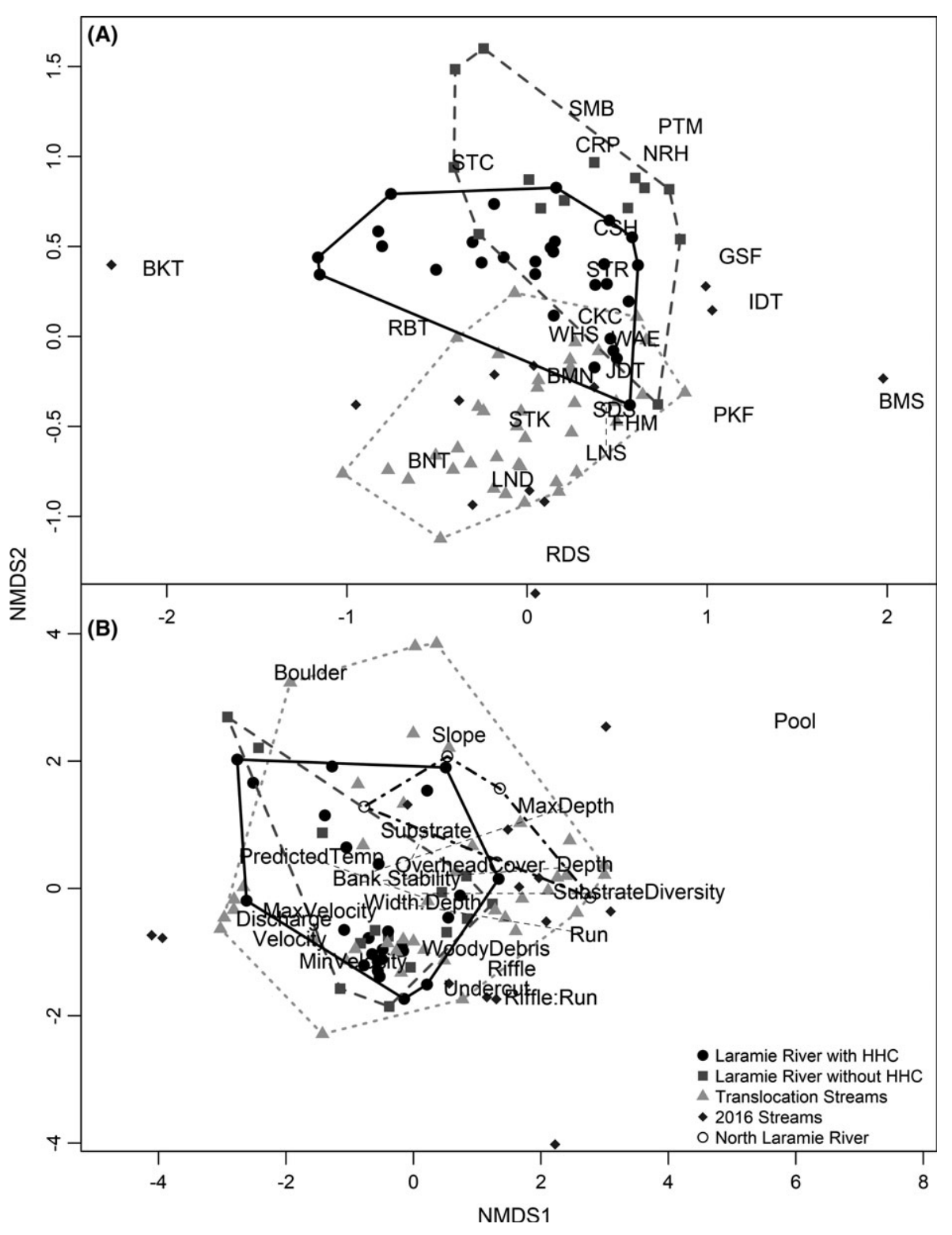

FIGURE 3. (A) Nonmetric multidimensional scaling (NMDS) ordination of the fish community for Laramie River sites occupied by Hornyhead Chub (HHC); Laramie River sites at which HHC were absent; translocation sites sampled in both 2016 and 2017; and translocation sites sampled only in 2016. Fish community variation between HHC-occupied and HHC-absent Laramie River sites was largely influenced by the presence of Smallmouth Bass. Three-letter labels are species codes and indicate how fish species were distributed in ordination space $(\mathrm{BKT}=\mathrm{Brook}$ Trout Salvelinus fontinalis; RBT $=$ Rainbow Trout Oncorhynchus mykiss; $\mathrm{STC}=$ Stonecat; $\mathrm{SMB}=$ Smallmouth Bass; CRP $=$ Common Carp Cyprinus carpio; $\quad$ PTM $=$ Plains Topminnow Fundulus sciadicus; $\mathrm{NRH}=$ Shorthead Redhorse Moxostoma macrolepidotum; CSH $=\mathrm{Common} \quad$ Shiner; $\mathrm{GSF}=$ Green Sunfish Lepomis cyanellus; $\mathrm{STR}=$ Central Stoneroller Campostoma anomalum $;$ IDT $=$ Iowa Darter Etheostoma exile $;$ BMS $=$ Bigmouth Shiner Notropis dorsalis; $\mathrm{PKF}=$ Plains Killifish Fundulus zebrinus; $\mathrm{CKC}=$ Creek Chub; WHS $=$ White Sucker Catostomus commersonii; $\mathrm{WAE}=$ Walleye Sander vitreus; JDT $=$ Johnny Darter Etheostoma nigrum; BMN $=$ Brassy Minnow Hybognathus hankinsoni; LNS $=$ Longnose Sucker; SDS $=$ Sand Shiner Notropis stramineus; FHM = Fathead Minnow Pimephales promelas; STK = Brook Stickleback Culaea inconstans; LND = Longnose Dace Rhinichthys cataractae $;$ RDS $=$ Red Shiner Cyprinella lutrensis; BNT = Brown Trout Salmo trutta). (B) The NMDS ordination of habitat for all sites, with the addition of North Laramie River sites, is presented. Laramie River sites with and without HHC occupy largely the same ordination space. The position of North Laramie River sites suggests that habitat conditions in addition to those found in the Laramie River are suitable for HHC. Locations of labels indicate how sites differed with respect to habitat in ordination space, and dashed lines indicate the original positions of labels that were moved for improved readability.

a Pearson's $r$ of 0.705 and an $r_{S}$ value of 0.729 . Bootstrapped RMSE for the model was 25.87. There were two comparable models within two $\mathrm{AIC}_{c}$ points of our top model. Both comparable models were in the backwater refuge hypothesis category, but one replaced the cascade habitat term with substrate diversity in the count process, 
and the other did not include width-to-depth ratio in the zero hurdle. Predicted abundance of Hornyhead Chub at translocation sites using the top model ranged from 0.96 to 273.25 (fish per $100 \mathrm{~m}$ ), with a median predicted abundance of 9.41 (Appendix Table A.1). The uppermost site in the Sweetwater River had by far the highest predicted abundance of Hornyhead Chub (273.25; Tables 2, A.1).

TABLE 2. Top-10 translocation sites with the highest rank totals. Ranks are shown for all three analyses: hurdle-model-predicted abundance of Hornyhead Chub (fish per $100 \mathrm{~m}$ ), habitat nonmetric multidimensional scaling (NMDS) distance, and fish community NMDS distance. Numbers in stream identification codes (ID) represent longitudinal locations from upstream (1) to downstream (8).

\begin{tabular}{lcccc}
\hline Site ID & $\begin{array}{c}\text { Model } \\
\text { prediction }\end{array}$ & $\begin{array}{c}\text { Habitat } \\
\text { NMDS }\end{array}$ & $\begin{array}{c}\text { Fish } \\
\text { NMDS }\end{array}$ & $\begin{array}{c}\text { Rank } \\
\text { total }\end{array}$ \\
\hline Sweetwater River 6 & 16 & 12 & 11 & 39 \\
Sweetwater River 1 & 1 & 1 & 38 & 40 \\
Sweetwater River 2 & 22 & 4 & 16 & 42 \\
Horseshoe Creek 5 & 25 & 7 & 13 & 45 \\
Box Elder Creek 6 & 7 & 6 & 36 & 49 \\
Horse Creek 4 & 38 & 11 & 6 & 55 \\
Horseshoe Creek 8 & 50 & 3 & 2 & 55 \\
Sweetwater River 3 & 10 & 25 & 22 & 57 \\
Box Elder Creek 3 & 5 & 41 & 12 & 58 \\
Box Elder Creek 4 & 9 & 20 & 32 & 61 \\
\hline
\end{tabular}

Our NMDS analysis of the fish community converged on a solution after 20 iterations, with a stress value of 0.176 (Figure 3A). A Shepard plot of ordination distances against the original dissimilarity distances suggested that our NMDS ordination preserved the distances well $\left(R^{2}=0.877\right)$. Hornyhead Chub-occupied sites on the Laramie River were characterized by fish communities containing the Common Shiner, Creek Chub, White Sucker,
Longnose Sucker, and Rainbow Trout (Figure 3A). The fish community at Laramie River sites without Hornyhead Chub was characterized by Common Carp, Shorthead Redhorse, Green Sunfish, and Smallmouth Bass (Figure 3A). The first axis characterized a gradient of fish species from coldwater (Brook Trout and Rainbow Trout) to warmwater (Common Carp and Green Sunfish) as NMDS axis values increased (Figure $3 \mathrm{~A}$ ). The second axis separated many translocation stream fish communities from the communities at Laramie River sites that lacked Hornyhead Chub. This is due to the increased proportion of Brown Trout and Longnose Dace at many translocation streams relative to Laramie River sites. In terms of fish community composition, Horse Creek sites tended to be the most similar to Hornyhead Chub-occupied Laramie River sites.

Our NMDS analysis of habitat converged on a solution after 20 iterations, with a stress value of 0.163 (Figure 3B). A Shepard plot of ordination distances against the original dissimilarity distances suggested that our NMDS ordination preserved the distances well $\left(R^{2}=0.888\right)$. Hornyhead Chub-occupied Laramie River sites shared much of the same ordination space as Laramie River sites at which Hornyhead Chub were absent. North Laramie River sites only partially overlapped with Hornyhead Chub-occupied sites. In particular, translocation sites tended to have a greater variation in stream discharge, stream slope, amount of boulder cover, and proportion of pool and riffle habitats. In terms of habitat conditions, Sweetwater River sites tended to be the most similar to Hornyhead Chub-occupied Laramie River sites.

Rank totals for translocation sites ranged between 39 and 147, with a median rank total of 76 (Table 2; Figure 4). The sites with the three highest rank totals were all located on the Sweetwater River (rank totals $=39$, 40, and 42). The sites with the top-10 highest rank totals occurred on the Sweetwater River (4 sites), Box Elder

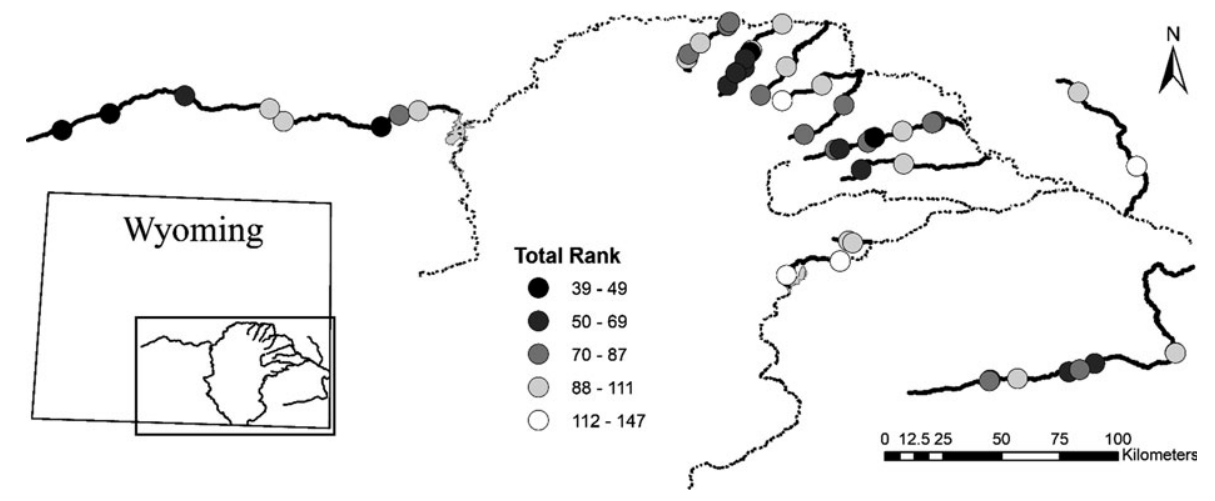

FIGURE 4. Translocation stream study area within Wyoming, with site symbols shaded from dark (sites with the highest rank totals) to light (sites with the lowest rank totals). The top-three sites with the highest rank totals were located on the Sweetwater River; other sites with high rank totals occurred on Box Elder, Horseshoe, and Horse creeks (see Figure 2 for study stream labels). 
Creek (3 sites), Horseshoe Creek (2 sites), and Horse Creek (1 site; Table 2). Spearman's rank correlation between the three methods was inconsistent and varied widely. The $r_{S}$ between habitat NMDS ranks and fish NMDS ranks was 0.110 ; the $r_{S}$ between habitat NMDS ranks and model-predicted abundance ranks was 0.077; and the $r_{S}$ between fish NMDS ranks and model-predicted abundance was -0.356 . All three analysis methods had higher $r_{S}$ values in correlations with the rank total (model-predicted abundance: $r_{S}=0.368$; fish NMDS: $r_{S}=0.482$; habitat NMDS: $r_{S}=0.656$ ), but overall rank correlations were low among methods.

\section{DISCUSSION}

Wyoming Hornyhead Chub populations are at risk of extirpation due to stochastic disturbances (e.g., the 2012 Arapahoe Fire that extirpated the North Laramie River population) and introductions of nonnative species, especially Smallmouth Bass. We used multiple approaches to identify sites that were structurally similar to the Laramie River in terms of both fish community and habitat so as to identify the best potential translocation sites. The lack of correlation among the ranking methods highlighted the importance of multiple methods. It is valuable to use multiple methods to take into account uncertainty in habitat and fish community requirements, which is often the case for small, isolated populations of at-risk species. By combining these approaches, we were able to identify the sites that are most likely to support a translocated population of Hornyhead Chub. Our results are provisional; ultimately, the only way to validate our ranking of sites is to translocate Hornyhead Chub and monitor for their establishment (Schumann et al. 2017).

Our approach for evaluating translocation sites represents a potential improvement over other assessment frameworks for rare or isolated populations. Other approaches have based scoring systems on limiting habitat, which often is unknown for less well-studied populations like Wyoming Hornyhead Chub. Assessments have focused on well-studied species (Eurasian beaver Castor fiber and Bull Trout Salvelinus confluentus) with many populations and for which specific habitat limitations (e.g., mean August stream temperature $<13^{\circ} \mathrm{C}$ for Bull Trout) are well known and understood (Macdonald et al. 2000; Dunham et al. 2011; Galloway et al. 2016). The disadvantage of these approaches in the case of species like Wyoming Hornyhead Chub is that we often have limited knowledge of specific habitat criteria, which are critical to informing such approaches. Our approach also used a scoring system with ranks but is a useful alternative for less well-studied species because it does not require knowledge of specific habitat criteria and can be applied to translocation sites over a large spatial extent.
The present approach improved our knowledge of Hornyhead Chub ecology by identifying specific factors that are most important for influencing the presence and abundance of Hornyhead Chub in the Laramie River. Our study highlighted the importance of a lack of Smallmouth Bass and the availability of backwater refuge habitat for Wyoming Hornyhead Chub. The importance of Smallmouth Bass is surprising, as Smallmouth Bass are sympatric with Hornyhead Chub throughout much of their distribution in the Midwest, where Smallmouth Bass prey on Hornyhead Chub but this predatory interaction does not lead to the latter species' extirpation (Becker 1983). Most previous work has suggested that habitat and water availability are the limiting factors for Hornyhead Chub. It has even been suggested that Hornyhead Chub might not be especially susceptible to predation because they often occur in sites with high habitat diversity, aquatic vegetation, and a diversity of other prey species (Mammoliti 2002). This does not appear to be the case in the Laramie River and may reflect (1) the more limited species and habitat diversity in the river and (2) that our study was carried out during years with good water availability.

All of the top hurdle models were backwater refuge models, highlighting the importance of access to refuge and/or backwater areas for Hornyhead Chub, and included terms for minimum water velocity, width-to-depth ratio, abundance of nonnative predators, and predicted temperature. Lower width-to-depth ratios (deep and narrow reaches of stream) may provide reduced refuge, feeding, and spawning opportunities and may leave Hornyhead Chub in closer proximity with nonnative predators (Schlosser 1987, 1988). A surprisingly strong result across models was that Hornyhead Chub abundance was highest at sites with low minimum velocity. Low minimum water velocities might indicate the presence of velocity shelters or backwater areas, which appear to be very important for maintaining high Hornyhead Chub abundance in the Laramie River but have generally not been associated with chub abundance in the literature (Lonzarich and Quinn 1995). Substrate diversity was positively related to Hornyhead Chub abundance and likely is important for spawning site provisioning; this is unsurprising given the importance of spawning substrate for Hornyhead Chub (Vives 1990; Bestgen 2013). Most of our top model parameters appear to be influenced at least indirectly by nonnative predators (Smallmouth Bass, Brook Trout, Rainbow Trout, and Brown Trout), thus limiting the conclusions we can make about broader Hornyhead Chub ecology.

The NMDS ordinations also supported the important role of Smallmouth Bass and successfully identified structural differences that were important for Hornyhead Chub among sites. For example, the fish community ordination delineated two distinct fish community assemblages in the Laramie River, where sites containing Hornyhead Chub 
overlapped little with sites containing Smallmouth Bass (Figure 3). Similarly, the only two Laramie River sites where both Hornyhead Chub and Smallmouth Bass were absent fell outside the Hornyhead Chub-occupied space in the habitat ordination, which indicates that this method can successfully represent differences in habitat structure that influence the presence of Hornyhead Chub. Our habitat ordination shows that the North Laramie River, where we documented reproduction in 2017 by recently reintroduced Hornyhead Chub, does not completely overlap with Laramie River sites (Figure 3). This indicates that habitat conditions beyond those present in the Laramie River will still allow for the persistence and reproduction of translocated Hornyhead Chub, but the direction of those habitats in ordination space is not predictable. Historically, Hornyhead Chub also occupied small spring creeks, which were potentially quite different from the currently occupied habitat in the Laramie River (Bestgen 2013).

Having just one site for characterizing fish-habitat relationships can result in several limitations. For example, the range of parameter values in the Laramie River may not reflect the range at translocation sites. As a result, we may be predicting to parameter values beyond those on which the hurdle model was trained, resulting in artificially high or low predictions of Hornyhead Chub abundance. In addition, the hurdle model only takes into account the fish community and habitat variables that varied in relation to the presence or abundance of Hornyhead Chub in the Laramie River. Variables like discharge and average substrate size did not vary in relation to Hornyhead Chub abundance in the Laramie River, so they were not included in the model. However, we know that Hornyhead Chub require gravel substrates to build nests (Vives 1990), and we would also expect a minimum discharge to be required for persistence. This study was carried out during two above-average flow years, so the importance of discharge is unclear, but previous work suggests that it can be a limiting factor in low-flow years (Bestgen 2013). We suggest that results should be used as a relative rather than absolute measure (hence our ranking approach) and consequently should be interpreted with caution.

Identification of the best available translocation sites is difficult because the main limiting factor for the Laramie River Hornyhead Chub population is not present at potential translocation sites. The absence of Smallmouth Bass is good for potential translocation success but does not assist in selecting among translocation sites where Smallmouth Bass are absent. Our results suggest that the potential for Hornyhead Chub translocation success is highest in the Sweetwater River, especially the Devil's Gate area (Sweetwater River 6; Table 2). Sweetwater River sites scored well overall because they possess fish community and habitat conditions similar to those at Hornyhead Chub-occupied sites on the Laramie River.
Few nonnative predators were present in the Sweetwater River, and they mostly consisted of Brown Trout (0-10 individuals per site) and Rainbow Trout (0-5 individuals per site), so the potential for competition and predation to prevent establishment of Hornyhead Chub is likely low. Girard (1856) recorded the presence of Hornyhead Chub in the Sweetwater River, but the species was not found in any subsequent collections, and the ultimate cause of extirpation for this population is unknown. Stream habitat conditions may have improved since extirpation, but Hornyhead Chub likely could not recolonize the river because of dams and unsuitable habitat conditions between populations. The other historically occupied locality we evaluated, Rawhide Creek, did not score as well as the Sweetwater River because the conditions that likely led to initial extirpation (stream dewatering and excessive siltation) do not appear to have sufficiently improved to allow for the reintroduction of Hornyhead Chub (Bestgen 2013).

The major limiting factor for our study was that only one Hornyhead Chub population was available to study. Potential alternative approaches would be to only consider historical sites for reintroduction or to use historical data to create spatial models for predicting Hornyhead Chub occurrence on the landscape (Dunham et al. 2003; Schumann et al. 2017). Consideration of only reintroduction sites has proven to be generally unsuccessful across translocation efforts because of failure to address the initial causes of decline (Cochran-Biederman et al. 2015). Because we do not know the cause of extirpation for most Wyoming Hornyhead Chub populations and because individual site characteristics strongly influence persistence in reintroduced populations (Schumann et al. 2017), consideration of only reintroduction sites is likely not a good approach. We initially attempted to use spatial modeling and historical data to predict Hornyhead Chub occurrence on the landscape, but historical locality data for Hornyhead Chub are sparse and proved to be uninformative at the landscape scale (Oakes et al. 2005). Our approach likely represents the best method for evaluating translocation sites for fishes with few populations, restricted distributions, and poorly documented historical distributions. Validation of the method we present will require translocation of Hornyhead Chub to top-ranking translocation sites and subsequent monitoring for survival and recruitment. A potentially informative step in this process would be to translocate fish to multiple sites and identify factors leading to translocation success or failure (Sheller et al. 2006).

We used a data-driven approach to identify the best available translocation sites for Hornyhead Chub, which will allow limited resources for native species conservation to be used in areas where the potential for translocation success is greatest (Sheller et al. 2006). Our results provided interesting insights into the ecology of Wyoming 
Hornyhead Chub but also have general implications for translocation of isolated populations of at-risk species. When factors causing population extirpations are known, they can be crucial information for selecting between translocation sites (Cochran-Biederman et al. 2015). In the absence of known extirpation causes, we suggest that factors limiting the distribution of a species are important to identify (Groce et al. 2012; Galloway et al. 2016). Importantly, we learned that historical data are often sparse and that the limiting factors for existing populations may not be relevant at translocation sites. In the absence of crucial information about previous extirpations, researchers must be creative in their methods and will likely have to use multiple approaches in order to identify suitable translocation sites for fish and wildlife species with limited distributions.

\section{ACKNOWLEDGMENTS}

We thank the private landowners for their support and cooperation, without which this work would not have been possible. We are grateful to all of the seasonal technicians and volunteers who helped with data collection for this study. We appreciate Steve Gale, Paul Gerrity, and Gordon Edwards for invaluable assistance in the field and expert advice in project planning. Funding was provided by the Wyoming Game and Fish Department. Any use of trade, firm, or product names is for descriptive purposes only and does not imply endorsement by the U.S. Government. Data were collected under Chapter 33 Permit 1065 from the Wyoming Game and Fish Department and in accordance with Protocol 20160609AW00244-01 approved by the Institutional Animal Care and Use Committee at the University of Wyoming. There is no conflict of interest declared in this article.

\section{REFERENCES}

Al-Chokhachy, R., M. Peacock, L. G. Heki, and G. Thiede. 2009. Evaluating the reintroduction potential of Lahontan Cutthroat Trout in Fallen Leaf Lake, California. North American Journal of Fisheries Management 29:1296-1313.

Armstrong, D. P., and P. J. Seddon. 2008. Directions in reintroduction biology. Trends in Ecology and Evolution 23:20-25.

Baxter, G. T., and M. Stone. 1995. Fishes of Wyoming. Wyoming Game and Fish Department, Cheyenne.

Becker, C. G. 1983. Fishes of Wisconsin. University of Wisconsin Press, Madison.

Bestgen, K. R. 2013. Distribution, habitat, and ecology of Hornyhead Chub Nocomis biguttatus in southeastern Wyoming. Final Report prepared for Wyoming Game and Fish Department, Cheyenne by Colorado State University, Fort Collins.

Bray, R. J., and J. T. Curtis. 1957. An ordination of the upland forest communities of southern Wisconsin. Ecological Monographs 27:325-349.

Brown, D. K., A. A. Echelle, D. L. Propst, J. E. Brooks, and W. L. Fisher. 2001. Catastrophic wildfire and number of populations as factors influencing risk of extinction for Gila Trout (Oncorhynchus gilae). Western North American Naturalist 61:139-148.

Burnham, K. P., and D. R. Anderson. 2002. Model selection and multimodel inference: a practical information-theoretic approach, 2nd edition. Springer Verlag, New York.

Cochran-Biederman, J. L., K. E. Wyman, W. E. French, and G. L. Loppnow. 2015. Identifying correlates of success and failure of native freshwater fish reintroductions. Conservation Biology 29:175-186.

Cross, F. B., and J. T. Collins. 1995. Fishes in Kansas. University of Kansas Natural History Museum, Public Education Series Number 14, Lawrence.

Cucherousset, J., and J. D. Olden. 2011. Ecological impacts of nonnative fishes. Fisheries 36:215-230.

Cummins, K. W. 1962. An evaluation of some techniques for the collection and analysis of benthic samples with special emphasis on lotic waters. American Midland Naturalist 67:477-504.

Dunham, J., K. Gallo, D. Shively, C. Allen, and B. Goehring. 2011. Assessing the feasibility of native fish reintroductions: a framework applied to threatened Bull Trout. North American Journal of Fisheries Management 31:106-115.

Dunham, J., B. D. Rieman, and G. Chandler. 2003. Influences of temperature and environmental variables on the distribution of Bull Trout within streams at the southern margin of its range. North American Journal of Fisheries Management 28:894-904.

Dunn, C. G., and P. L. Angermeier. 2016. Development of habitat suitability indices for the Candy Darter, with cross-scale validation across representative populations. Transactions of the American Fisheries Society 145:1266-1281.

Echelle, A. A., M. R. Schwemm, N. J. Lang, B. C. Nagle, A. M. Simons, P. J. Unmack, W. L. Fisher, and C. W. Hoagstrom. 2014. Molecular systematics and historical biogeography of the Nocomis biguttatus species group (Teleostei: Cyprinidae): nuclear and mitochondrial introgression and a cryptic Ozark species. Molecular Phylogenetics and Evolution 81:109-119.

Fagan, W. F. 2002. Connectivity, fragmentation, and extinction risk in dendritic metapopulations. Ecology 83:3243-3249.

Fausch, K. D., J. Lyons, J. R. Karr, and P. L. Angermeier. 1990. Fish communities as indicators of environmental degradation. Pages 123 144 in S. M. Adams, editor. Biological indicators of stress in fish. American Fisheries Society, Symposium 8, Bethesda, Maryland.

Fitzgerald, D. G., E. Kott, R. P. Lanno, and D. G. Dixon. 1998. A quarter century of change in the fish communities of three small streams modified by anthropogenic activities. Journal of Aquatic Ecosystem Stress and Recovery 6:11-127.

Galloway, B. T., C. C. Muhlfeld, C. S. Guy, C. C. Downs, and W. A. Fredenberg. 2016. A framework for assessing the feasibility of native fish conservation translocations: applications to threatened Bull Trout. North American Journal of Fisheries Management 36:754-768.

George, A. L., B. R. Kuhajda, J. D. Williams, M. A. Cantrell, P. L. Rakes, and J. R. Shute. 2009. Guidelines for propagation and translocation for freshwater fish conservation. Fisheries 34:529-545.

Gido, K. B., W. K. Dodds, and M. E. Eberle. 2010. Retrospective analysis of fish community change during a half century of land use and streamflow change. Journal of the North American Benthological Society 29:970-987.

Girard, C. 1856. Researches upon the cyprinoid fishes inhabiting the fresh waters of the United States west of the Mississippi Valley, from specimens in the museum of the Smithsonian Institution. Proceedings of the Academy of Natural Sciences of Philadelphia 8:165213.

Groce, M. C., L. L. Bailey, and K. D. Fausch. 2012. Evaluating the success of Arkansas Darter translocations in Colorado: an occupancy sampling approach. Transactions of the American Fisheries Society $141: 825-840$. 
Hawkins, C. P., J. L. Kershner, P. A. Bisson, M. D. Bryant, L. M. Decker, S. V. Gregory, D. A. McCullough, C. K. Overton, G. H Reeves, R. J. Steedman, and M. K. Young. 1993. A hierarchical approach to classifying stream habitat features. Fisheries 18(6):3-12.

Hickerson, B. T. 2018. Conservation and recovery of Hornyhead Chub. Master's thesis. University of Wyoming, Laramie.

Isaak, D., B. Rieman, and D. Horan. 2009. A watershed-scale monitoring protocol for Bull Trout. U.S. Forest Service General Technical Report RMRS-GTR-224.

Jackman, S. 2017. pscl: classes and methods for R. R package version 1(5):2.

Lachner, E. A., and R. E. Jenkins. 1971. Systematics, distribution, and evolution of the Nocomis biguttatus species group (Family Cyprinidae: Pisces) with description of a new species from the Ozark Upland. Smithsonian Institution Press, Smithsonian Contributions to Zoology 91, Washington, D.C.

Lonzarich, D. G., and T. P. Quinn. 1995. Experimental evidence for the effect of depth and structure on the distribution, growth, and survival of stream fishes. Canadian Journal of Zoology 73:2223-2230.

Lyon, J. P., and J. P. O'Connor. 2008. Smoke on the water: can riverine fish populations recover following a catastrophic fire-related sediment slug? Austral Ecology 33:794-806.

Macdonald, D. W., F. H. Tattersall, S. Rushton, A. B. South, R. Shaila, P. Maitland, and R. Strachan. 2000. Reintroducing the beaver (Castor fiber) to Scotland: a protocol for identifying and assessing suitable release sites. Animal Conservation 3:125-133.

Mammoliti, C. S. 2002. The effects of small watershed impoundments on native stream fishes: a focus on the Topeka Shiner and Hornyhead Chub. Transactions of the Kansas Academy of Science 105:219-231.

Miltner, R. J., D. Wahite, and C. Yoder. 2004. The biotic integrity of streams in urban and suburbanizing landscapes. Landscape and Urban Planning 69:87-100.

Oakes, R. M., K. B. Gido, J. A. Falke, J. D. Olden, and B. L. Brock. 2005. Modeling of stream fishes in the Great Plains, USA. Ecology of Freshwater Fish 14:361-374.

Ogle, D. H. 2017. FSA: Fisheries Stock Analysis. R package version 0.8.17.

Oksanen, J., F. G. Blanchet, M. Friendly, R. Kindt, P. Legendre, D. Minchin, R. B. O'Hara, G. L. Simpson, P. Solymos, M. H. Stevens, E. Szoecs, and H. Wagner. 2017. Vegan: community ecology package. $\mathrm{R}$ package version 2.4-5.

Perkin, J. S., K. B. Gido, K. H. Costigan, M. D. Daniels, and E. R. Johnson. 2014. Fragmentation and drying ratchet down Great Plains stream fish diversity. Aquatic Conservation: Marine and Freshwater Ecosystems 25:639-655.

Potts, J. M., and J. Elith. 2006. Comparing species abundance models. Ecological Modelling 199:153-163.
Propst, D. L., and C. A. Carlson. 1986. The distribution and status of warmwater fishes in the Platte River drainage, Colorado. Southwestern Naturalist 31:149-167.

Roghair, C. N., C. A. Dolloff, and M. K. Underwood. 2002. Response of a Brook Trout population and instream habitat to a catastrophic flood and debris flow. Transactions of the American Fisheries Society 131:718-730.

Rowe, D. C., C. L. Pierce, and T. F. Wilton. 2009. Fish assemblage relationships with physical habitat in wadeable Iowa streams. North American Journal of Fisheries Management 29:1314-1332.

Ruetz, C. R., D. G. Uzarski, D. M. Krueger, and E. S. Rutherford. 2007. Sampling a littoral fish assemblage: comparison of small-mesh fyke netting and boat electrofishing. North American Journal of Fisheries Management 27:825-831.

Schlosser, I. J. 1987. The role of predation in age- and size-related habitat use by stream fishes. Ecology 68:651-659.

Schlosser, I. J. 1988. Predation risk and habitat selection by two size classes of a stream cyprinid: experimental test of a hypothesis. Oikos 2:36-40.

Schumann, D. A., W. W. Hoback, K. D. Koupal, C. W. Schoenebeck, S. C. Schainost, and T. L. Wilson. 2017. Experimental analysis of reintroduction strategies to conserve the vulnerable Plains Topminnow Fundulus sciadicus in Nebraska. Endangered Species Research 34:349-355.

Sheller, F. J., W. F. Fagan, and P. J. Unmack. 2006. Using survival analysis to study translocation success in the Gila Topminnow (Poeciliopsis occidentalis). Ecological Applications 16:1771-1784.

Spurgeon, J. J., C. P. Paukert, B. D. Healy, M. Trammell, D. Speas, and E. Omana-Smith. 2015. Translocation of Humpback Chub into tributary streams of the Colorado River: implications for conservation of large-river fishes. Transactions of the American Fisheries Society 144:502-514.

Streyerberg, E. W., F. E. Harrell, G. J. J. M. Borsboom, M. J. C. Eijkemans, Y. Vergouwe, and J. D. F. Habbema. 2001. Internal validation of predictive models: efficiency of some procedures for logistic regression analysis. Journal of Clinical Epidemeology 54:741-781.

Vives, S. P. 1990. Nesting ecology and behavior of Hornyhead Chub Nocomis biguttatus, a keystone species in Allequash Creek. Wisconsin. American Midland Naturalist 124:46-56.

WGFD (Wyoming Game and Fish Department). 2015. Annual fisheries progress report on the 2015 work schedule. WGFD, Cheyenne.

Zuur, A. F., E. N. Ieno, and G. M. Smith. 2007. Analysing ecological data. Springer, New York.

Zuur, A. F., E. N. Ieno, N. J. Walker, A. A. Saveliev, and G. M. Smith. 2009. Mixed effects models and extensions in ecology with R. Springer, New York.

\section{Appendix: Model-Predicted Hornyhead Chub Abundance and Ordination Distances}

TABLE A.1. Model-predicted Hornyhead Chub abundance (fish per $100 \mathrm{~m}$ ) and fish community and habitat nonmetric multidimensional scaling (NMDS) ordination distances for all 54 translocation sites, with rank scores for each method given in parentheses. Numbers in translocation site identification codes (ID) correspond to the longitudinal stream location $(1=$ upstream; $8=$ downstream). Sites are ordered from highest rank total to lowest rank total.

\begin{tabular}{lccc}
\hline Site ID & Predicted abundance & Fish NMDS distance & Habitat NMDS distance \\
\hline Sweetwater River 6 & $21.20(16)$ & $0.612(11)$ & $1.326(12)$ \\
Sweetwater River 1 & $273.25(1)$ & $1.178(38)$ & $0.668(1)$ \\
Sweetwater River 2 & $14.38(22)$ & $0.766(16)$ & $0.812(4)$ \\
Horseshoe Creek 5 & $11.26(25)$ & $0.642(13)$ & $0.918(7)$ \\
Box Elder Creek 6 & $43.68(7)$ & $1.147(36)$ & $0.847(6)$
\end{tabular}


TABLE A.1. Continued.

\begin{tabular}{|c|c|c|c|}
\hline Site ID & Predicted abundance & Fish NMDS distance & Habitat NMDS distance \\
\hline Horse Creek 4 & $5.41(38)$ & $0.550(6)$ & $1.174(11)$ \\
\hline Horseshoe Creek 8 & $2.24(50)$ & $0.460(2)$ & $0.801(3)$ \\
\hline Sweetwater River 3 & $39.98(10)$ & $0.862(22)$ & $2.243(25)$ \\
\hline Box Elder Creek 3 & $57.34(5)$ & $0.638(12)$ & $3.001(41)$ \\
\hline Box Elder Creek 4 & $41.05(9)$ & $1.079(32)$ & $2.032(20)$ \\
\hline Horse Creek 2 & $7.22(34)$ & $0.578(8)$ & $2.103(22)$ \\
\hline Horseshoe Creek 2 & $27.00(13)$ & $1.113(34)$ & $1.739(17)$ \\
\hline Box Elder Creek 2 & $37.88(11)$ & $1.219(41)$ & $1.401(13)$ \\
\hline Horse Creek 6 & $2.43(46)$ & $0.146(1)$ & $1.862(18)$ \\
\hline Cottonwood Creek 1 & $16.13(20)$ & $0.816(20)$ & $2.246(26)$ \\
\hline Horseshoe Creek 4 & $9.26(29)$ & $0.803(18)$ & $1.874(19)$ \\
\hline Box Elder Creek 5 & $75.71(2)$ & $1.281(45)$ & $2.038(21)$ \\
\hline Box Elder Creek 1 & $68.56(4)$ & $1.072(31)$ & $2.573(34)$ \\
\hline La Bonte Creek 2 & $8.20(31)$ & $0.520(4)$ & $2.573(35)$ \\
\hline Horseshoe Creek 1 & $37.39(12)$ & 0.815 (19) & $2.860(40)$ \\
\hline Horseshoe Creek 7 & $4.55(42)$ & $0.922(25)$ & $0.837(5)$ \\
\hline Horse Creek 5 & $2.33(47)$ & $0.920(24)$ & $0.724(2)$ \\
\hline La Prele Creek 1 & $73.63(3)$ & $1.219(40)$ & $2.351(30)$ \\
\hline Deer Creek 7 & $6.03(36)$ & $1.045(29)$ & $1.057(9)$ \\
\hline Deer Creek 8 & $8.84(30)$ & $0.775(17)$ & $2.282(28)$ \\
\hline Horseshoe Creek 3 & $21.73(15)$ & $0.601(9)$ & $4.164(51)$ \\
\hline Horse Creek 1 & $9.61(26)$ & $0.573(7)$ & $3.179(43)$ \\
\hline Sweetwater River 7 & $5.05(40)$ & $0.957(26)$ & $1.154(10)$ \\
\hline Horse Creek 8 & $1.01(53)$ & $0.532(5)$ & $2.239(24)$ \\
\hline La Bonte Creek 1 & $44.38(6)$ & $1.333(46)$ & $2.419(32)$ \\
\hline Deer Creek 4 & $13.40(23)$ & $1.563(50)$ & $1.599(14)$ \\
\hline Sweetwater River 5 & $3.83(44)$ & $1.175(37)$ & $1.040(8)$ \\
\hline Deer Creek 6 & $41.91(8)$ & $1.140(35)$ & $3.616(47)$ \\
\hline Horse Creek 3 & $3.77(45)$ & $0.489(3)$ & $3.148(42)$ \\
\hline Horseshoe Creek 6 & $2.31(48)$ & $0.859(21)$ & $2.229(23)$ \\
\hline La Prele Creek 2 & $6.83(35)$ & $0.604(10)$ & $4.529(52)$ \\
\hline Box Elder Creek 7 & $16.83(19)$ & $1.059(30)$ & $3.707(49)$ \\
\hline Sweetwater River 4 & $2.28(49)$ & $0.918(23)$ & $2.247(27)$ \\
\hline Horse Creek 7 & $1.05(52)$ & $0.744(15)$ & $2.489(33)$ \\
\hline Wagonhound Creek 2 & $9.56(27)$ & $1.277(44)$ & $2.286(29)$ \\
\hline Duck Creek 1 & $7.56(33)$ & $2.329(52)$ & $1.712(16)$ \\
\hline Deer Creek 1 & $17.27(18)$ & $1.530(49)$ & $2.673(36)$ \\
\hline Rawhide Creek 1 & $5.36(39)$ & $0.974(27)$ & $2.679(37)$ \\
\hline Box Elder Creek 8 & $17.80(17)$ & $1.229(42)$ & $3.600(46)$ \\
\hline Duck Creek 2 & $5.95(37)$ & $2.329(53)$ & $1.601(15)$ \\
\hline Sweetwater River 8 & $4.79(41)$ & $1.085(33)$ & $2.405(31)$ \\
\hline Deer Creek 5 & $9.27(28)$ & $1.239(43)$ & $2.696(38)$ \\
\hline Cottonwood Creek 2 & $11.53(24)$ & $1.213(39)$ & $3.673(48)$ \\
\hline Upper Laramie River 2 & $0.96(54)$ & $0.729(14)$ & $3.569(45)$ \\
\hline Deer Creek 3 & $7.91(32)$ & $1.337(47)$ & $2.708(39)$ \\
\hline Deer Creek 2 & $14.45(21)$ & $1.354(48)$ & $4.060(50)$ \\
\hline Wagonhound Creek 1 & $25.41(14)$ & $2.329(54)$ & $5.448(54)$ \\
\hline Upper Laramie River 1 & $1.57(51)$ & $1.029(28)$ & $3.410(44)$ \\
\hline Rawhide Creek 2 & $3.87(43)$ & $2.043(51)$ & $4.725(53)$ \\
\hline
\end{tabular}

